\title{
Current and future health care professionals attitudes toward and knowledge of statistics: How confidence influences learning
}

\author{
Heibatollah Baghi ${ }^{1}$, Melanie L. Kornides ${ }^{2}$ \\ 1. Department of Global and Community Health, George Mason University, USA. 2. Department of Epidemiology, Harvard \\ School of Public Health, USA
}

Correspondence: Heibatollah Baghi. Address: 4400 University Drive, MS 5B7, Fairfax, VA 22030, USA. Email: hbaghi@gmu.edu.

Received: July 19, 2012

DOI : $10.5430 /$ jnep.v3n7p24

Accepted: August 27, 2012

URL: http://dx.doi.org/10.5430/jnep.v3n7p24

Online Published: January 9, 2013

\section{Abstract}

Background: Health care professionals require some understanding of statistics to successfully implement evidence based practice. Developing competency in statistical reasoning is necessary for students training in health care administration, research, and clinical care. Recently, the interest in healthcare professional's attitudes toward statistics has increased substantially due to evidence that these attitudes can hinder professionalism developing an understanding of statistical concepts.

Methods: In this study, we analyzed pre- and post-instruction attitudes towards and knowledge of statistics obtained from health science graduate students, including nurses and nurse practitioners, enrolled in an introductory graduate course in statistics $(n=165)$.

Results and Conclusions: Results show that the students already held generally positive attitudes toward statistics at the beginning of course. However, these attitudes—along with the students' statistical proficiency-improved after 10 weeks of instruction. The results have implications for curriculum design and delivery methods as well as for health professionals' effective use of statistics in critically evaluating and utilizing research in their practices.

\section{Key words}

Nursing education, Statistical education

\section{Introduction}

An essential component of nursing education is ensuring students develop the competencies in the use of empirical evidence in their clinical practice ${ }^{[1,2]}$. The fundamental goal of statistics courses is to teach healthcare professionals the proper uses of statistical thinking to enable them to effectively evaluate the literature and integrate evidence into their practice ${ }^{[3]}$. However, nursing students often have anxiety toward statistics due to their fear of mathematics. Healthcare practitioners frequently find statistics courses a daunting challenge due to their perceptions of the subject's complexity and their lack of a strong background in mathematics ${ }^{[4]}$. Nurses' attitudes may influence their learning of statistical skills as much as their cognitive abilities. The impact of attitudes toward statistics on the development of statistical reasoning 
ability and the understanding of statistical concepts has been studied, and practitioners' attitudes have been shown to influence their statistical performance ${ }^{[5-8]}$. Because of the increasing number of nurses and other health care practitioners returning for graduate study in health science programs, it is important to assess these professionals' attitudes toward statistics and explore ways to improve them.

The purpose of this study was to measure health science students' attitudes toward statistics and their statistical proficiency both before and after a 10-week introductory graduate statistics course. The results have implications for curriculum design and delivery methods as well as for health professionals' effective use of statistics in evidence-based practice.

\section{Subjects and methods}

\subsection{Participants}

The study participants were 165 graduate students enrolled in an introductory graduate course in statistics at a large research university in northern Virginia. Students were exclusively healthcare majors, including 58 currently practicing registered nurses and/or nurse practitioners and clinical nurse specialists, and the course was required for the Master of Science programs in which they were enrolled. The students reported a 3.34 mean GPA. The students were predominantly white females. Of the participants, 82 were U.S. citizens and 83 were international students. Each participant completed a self-reported instrument to measure (a) attitudes toward statistics using a 5-point Likert-type scale and (b) statistical proficiency. The assessment was done at the beginning and the end of a 10-week introductory graduate-level course in statistics.

\subsection{Measurement of attitudes and statistical knowledge}

Criterion-referenced tests were constructed for pre/post measures of (a) attitudes toward statistics and (b) students' statistical proficiency level. The national Standards for Educational and Psychological Testing guided the scale development ${ }^{[9]}$.

\subsubsection{Measures of attitudes toward statistics}

The attitude instrument was developed through literature consultation ${ }^{[10-12]}$ interviews with content experts, comprised of six instructors of statistics, and the researcher's personal experience. In the instrument, the attitudes toward statistics were defined as falling in six domains: (a) knowledge of research design (how much a person thinks he/she knows about quantitative research design), (b) knowledge of statistical computation, (c) knowledge of statistical application, (d) knowledge of statistical interpretation, (e) utility (the extent to which person believes that statistical tools are useful in the his/her work, and (f) self-confidence in the utilization of statistics. The assumption in the study was that the six domains (i.e., constructs) have a significant impact on students' performance in statistics. The six constructs were subsequently translated into scale items that were intended to reflect the essential elements of the domains. An initial pool of 40 items was developed and was evaluated by the six statistics instructors for content validity evidence; then reduced to 25 items for ease in administering the instrument. The content validity index ${ }^{[12]}$ for this instrument was .88, and all six content experts indicated that the 25 items appropriately represented the domains of the content. A 5-point Likert-type scale used to rate the items ( 1 = strongly disagree; 2 = somewhat disagree; $3=$ neither agree nor disagree; $4=$ somewhat agree; 5 = strongly agree).

\subsubsection{Statistical proficiency test}

The proficiency test had five sub-skill areas: (a) descriptive statistics, (b) correlational analysis, (c) hypothesis testing, (d) regression analysis, and (e) group differences statistical procedures (e.g., independent t-test and analysis of variance). These components were also derived by the six instructors who were teaching introductory graduate courses in heath 
science statistics. These five sub-skill areas were subsequently translated into items intended to measure statistical proficiency. An initial pool of 40 items was developed and was evaluated by the six instructors for content representativeness. Content experts indicated that the 30 items appropriately represented the domains of the statistical content. Content validity is defined in the Standards for Education and Psychological Testing as logical or empirical analysis of the adequacy with which test content represents the content domain ${ }^{[9]}$. To provide evidence of the validity of this statistical test, the test was reviewed by the six experts who found all items to be content appropriate (content validity index $=.92$ ) [13].

\subsection{Procedure and data analysis}

The self-report survey instrument to measure attitudes toward statistics and statistical proficiency was administered to the 165 participants before and after 10 weeks of instruction in introductory statistics to measure students' possible improvement in attitudes. Pre- and post-test descriptive statistics were computed for each domain. This analysis allowed us to assess the internal consistency reliability of the scores obtained from the attitudes toward statistics for both administrations. To analyze internal consistency, Cronbach's alpha was computed for scores on the individual domains in the attitude scale ${ }^{[14]}$.To address the criterion-related validity of the measures of attitudes toward statistics, correlations were computed for the six domain scores with a composite made of the five domains of the statistical proficiency test ${ }^{[15]}$. Paired t-tests were used to examine the statistical significance of score changes in the difference between pre-test and post-test means ${ }^{[16]}$. This study was reviewed by the Human Subject Review Board (HSRB) at the George Mason University.

\section{Results}

A total of 165 students, including 58 registered nurses/nurse practitioners/ clinical nurse specialists, completed the attitude questionnaire and the statistical proficiency test both before and after the 10-week introductory statistics course. Six domains were chosen to characterize students' attitude toward statistics: research design, interpretation, application, computation, utility, and self-confidence. Internal consistency reliability (the degree to which scale items intercorrelate) of scores for the six domains was estimated by Cronbach's coefficient alpha. The reliabilities ranged from .63 for the utility domain to .88 for the application domain (see Table 3). Although the minimum recommended standard for Cronbach's alpha varies among psychometricians, Nunnaly and Bernstein recommend a threshold of $.70^{[17]}$. Intercorrelations among factors were low, with only one correlation above .20. Criterion-related validity of the scores for the attitude scale was investigated by correlating the six domain scores (pre- and post-test administrations) with a composite made of the five domains of the statistical proficiency test (see Tables 3 and 4). Among the six scales, self-confidence correlated lowest with the composite, while perceived knowledge of statistical computation and application correlated the highest. It indicates that statistical performance is more reflective of how much the student thinks he/she knows about statistical computation and interpretation than how important he/she thinks the quantitative methodology is.

\section{I mpact of intervention: Pre-test and Post-test scores}

Summary measures (mean and standard deviation of the scores) for pre-test and post-test administration of the attitude instrument for six domains are presented in Table 1. Pre-test and post-test assessments were compared using paired t-tests to find evidence of statistically significant improvements in the six domain scores, also shown in Table 1 . The paired t-test results indicated that there was a statistically significant change $(p<.01)$ in mean scores from pre-test to post-test administration, indicating an improvement in attitude scores. The only exception was the utility domain (the extent to which the student finds statistics useful in his or her work); for which the pre- and post- differences were not statistically significant. 
Table 1. Score Changes in Pretest and Posttest Administration of Students' Attitude toward Statistics

\begin{tabular}{|c|c|c|c|c|c|c|}
\hline \multirow{2}{*}{ Scale } & \multirow{2}{*}{$\mathbf{N}$} & \multicolumn{2}{|c|}{ Pretest } & \multicolumn{3}{|c|}{ Posttest } \\
\hline & & $\mathbf{M}$ & SD & $\mathbf{M}$ & SD & $t$ test \\
\hline Application & 165 & 2.16 & .86 & 3.80 & .84 & $20.96 * *$ \\
\hline Interpretation & 165 & 2.90 & .97 & 4.10 & .89 & $15.44 * *$ \\
\hline Research Design & 165 & 3.28 & 1.01 & 4.08 & .85 & $11.26^{* *}$ \\
\hline Computation & 165 & 3.44 & 1.01 & 4.36 & .82 & $12.27 * *$ \\
\hline Utility & 165 & 4.06 & .82 & 4.17 & .77 & 1.67 \\
\hline Self-Confidence & 165 & 2.59 & 1.1 & 2.88 & .67 & $3.09 *$ \\
\hline
\end{tabular}

$* p<.01, * * p<.001$

Summary measures for pre-test and post-test administration of the statistical proficiency test are presented in Table 2 . The paired $t$-test results indicate that there was a statistically significant change $(p<.01)$ in mean scores from pre-test to post-test administration, indicating improvement in statistical proficiency scores. The improvement was observed for each of the domains (descriptive, correlation, hypotheses testing, regression analysis, and group differences).

Table 2. Score Changes in Pretest and Posttest Administration of Students’ Statistical Proficiency Test.

\begin{tabular}{|c|c|c|c|c|c|c|}
\hline \multirow{2}{*}{ Scale } & \multirow{2}{*}{$\mathbf{N}$} & \multicolumn{2}{|c|}{ Pretest } & \multicolumn{2}{|c|}{ Posttest } & \multirow[b]{2}{*}{$t$ test } \\
\hline & & $\mathbf{M}$ & SD & $\mathbf{M}$ & SD & \\
\hline Descriptive & 165 & 4.05 & 1.40 & 4.92 & 1.08 & $8.09 * *$ \\
\hline Correlation & 165 & 2.27 & 1.39 & 3.78 & 1.56 & $11.67 * *$ \\
\hline Hypotheses Testing & 165 & 3.30 & 1.57 & 4.77 & 1.56 & $10.59 * *$ \\
\hline $\begin{array}{l}\text { Regression } \\
\text { Analysis }\end{array}$ & 165 & 1.50 & .954 & 2.36 & 1.34 & $8.07 * *$ \\
\hline Group Differences & 165 & 0.98 & 1.05 & 2.81 & 1.51 & $12.36 * *$ \\
\hline
\end{tabular}

** $p<.001$

Table 3. Reliability and Validity Estimates for Students’ Attitude toward Statistics (Pre-test Data)

\begin{tabular}{llll}
\hline Scale & $\mathbf{K}^{*}$ & Alpha $^{\#}$ & Validity Estimate $^{\wedge}$ \\
\hline Application & 8 & .88 & $.33^{* *}$ \\
Interpretation & 6 & .84 & $.25^{* *}$ \\
Research Design & 3 & .74 & $.31^{* *}$ \\
Computation & 3 & .71 & $.43 * *$ \\
Utility & 3 & .63 & $.28 * *$ \\
Self-Confidence & 2 & .65 & .13 \\
\hline
\end{tabular}

*. Number of Items; \#. Cronbach’s Alpha; ^. Correlation with Statistical Proficiency test;

$* * p<.001$

Table 4. Reliability and Validity Estimates for Students’ Attitude toward Statistics (Post-test Data)

\begin{tabular}{llll}
\hline Scale & $\mathbf{K}^{*}$ & Alpha $^{\#}$ & Validity Estimate $^{\wedge}$ \\
\hline Application & 8 & .90 & $.35^{* *}$ \\
Interpretation & 6 & .93 & $.34^{* *}$ \\
Research Design & 3 & .81 & $.33^{* *}$ \\
Computation & 3 & .86 & $.36 * *$ \\
Utility & 3 & .68 & $.25^{* *}$ \\
Self-Confidence & 2 & .50 & .14 \\
\hline
\end{tabular}

*. Number of Items; \#. Cronbach’s Alpha; ^. Correlation with Statistical Proficiency test

$* * p<.001$ 


\section{Discussion}

A solid foundation in statistical reasoning is essential for health care and health science professionals using evidencebased practice ${ }^{[2]}$. A failure to adequately use and/or understand the statistics in the literature may ultimately result in misapplication of the evidence to health care interventions. As a result, training in statistics is a core requirement of many graduate programs for nurses and other health care professionals. The present study concerned the associations between students' attitudes towards and learning of statistics over the course of a semester in a graduate program for health science majors. Based on the researcher's prior experience, it was expected that there would be a change in health science students' attitudes toward statistics and statistical knowledge/skills over the course of the semester. The importance of this study is that it presents empirical evidence to support these expectations.

Consistent with previous findings, the health science students and health care practitioners in the present study generally held positive attitudes toward statistics at the beginning of the course. However, their attitudes toward statistics improved after 10 weeks of instruction. A study implementing a series of research utilization workshops for health care professionals found participants' attitude toward research were positive before the workshops ${ }^{[18]}$. In addition, their fear of using research decreased after the workshops. These findings from the present study indicates that the commonly held belief among health science statistics instructors that health professionals enrolled in graduate study have negative attitudes toward statistics may in fact not be true.

As expected in the present study, statistical proficiency levels improved significantly after 10 weeks of instruction. In general, the positive attitudes could be the result of following the recommendations in the NCTM standards, which emphasize mathematics, statistics, and probability; the students' improved understanding of and appreciation for statistics, gained in the 10-week instruction, may have influenced their attitudes toward statistics. These results could offer an important element of summative feedback to the graduate students studying statistics in healthcare science programs. Research has documented that nurses with high belief in their capabilities to understand and process research are more likely to apply components of evidence-based practice ${ }^{[19]}$. Further research is needed to determine if these professionals use their statistical skills specifically when evaluating the health care literature.

The present study has several limitations. Convenience sampling was used, and there was not a comparison control group. The sample consisted of students in a variety of health science programs, including graduate nursing programs. The graduate nursing student sub-sample was not separately analyzed. Despite these limitations, the study presents evidence that nursing students and other health sciences students generally hold positive attitudes towards statistics, but their belief in their capabilities and overall attitudes improved upon 10 weeks of instruction. Health science programs seeking to improve their graduates' use of evidence-based practice may want to consider assessing their students attitudes towards research and statistics to help identify those students with low belief in their capabilities to understand research, and providing targeted statistical training in research utilization.

\section{Acknowledgement}

Melanie Kornides was supported by Training Grant T32HD060454 from the U.S. National Institutes of Health.

\section{References}

[1] Meeker MA, Jones JM, Flanagan NA: Teaching undergraduate nursing research from an evidence-based practice perspective. J Nurs Educ. 2008; 47(8): 376-379. PMid:18751652 http://dx.doi.org/10.3928/01484834-20080801-06

[2] Taylor S, Muncer S: Redressing the power and effect of significance. A new approach to an old problem: teaching statistics to nursing students. Nurse Educ Today. 2000; 20(5): 358-364. PMid:10895117 http://dx.doi.org/10.1054/nedt.2000.0429

[3] Schau C, Stevens J, Dauphinee TL, Vecchio AD: The Development and Validation of the Survey of Antitudes toward Statistics. Educational and Psychological Measurement. 1995; 55(5): 868-875. http://dx.doi.org/10.1177/0013164495055005022 
[4] Heaton RM, Mickelson WT: The Learning and Teaching of Statistical Investigation in Teaching and Teacher Education. Journal of Mathematics Teacher Education. 2002; 5(1): 35-59. http://dx.doi.org/10.1023/A:1013886730487

[5] Araki, L., R., \& Schultz, K., S. Students' attitudes toward statistics and their retention of statistical concepts. Paper presented at the annual meeting of the Western Psychological Association, Los Angeles, CA, 1995.

[6] Gal, I., \& Ginsburg, L. The role of beliefs and attitudes in learning statistics: Toward and assessment framework. Journal of Statistics Education. 1994; 2(2): 1-16.

[7] Garfield, J., \& Ahlgren, A. Difficulties in learning basic concepts in probability and statistics: Implications for research. Journal of Research in Mathematics Education. 1988; 19: 44-63. http://dx.doi.org/10.2307/749110

[8] Evans, B., R. Student attitudes, conceptions, and achievement in introductory undergraduate college statistics. Doctoral Dissertation, Temple University, 2005. Dissertation Abstracts International, AA13178774.

[9] American Educational Research Association (AERA), American Psychological Association (APA), \& National Council on Measurement in Education (NCME). Joint Committee on Standards. Standards for educational and psychological testing. Washington, DC, 1999.

[10] Bryant, N. C., \& Barnes L.B. Development and validation of the attitude toward educational measurement inventory. Educational and Psychological Measurement. 1997; 57 (5): 1037-1042. http://dx.doi.org/10.1177/0013164497057005011

[11] Wise, S. L. The development and validation of scale measuring attitudes toward statistics. Educational and Psychological Measurement. 1985; 45: 401-405.

[12] Chang, L. Quantitative Attitudes Questionnaire: Instrument development and validation. Educational and Psychological Measurement. 1996; 56 (6): 1037-1042. http://dx.doi.org/10.1177/0013164496056006009

[13] Waltz, C. F., Strickland, O. L., \& Lenz, E. R. Measurement in nursing and health research. (3rd ed.). New York: Springer, 2005.

[14] Nunnaly , J. C., \& Bernstein, I. H. Psychometric theory (3rd ed.). New York: McGraw-Hill, 1994.

[15] Pedazur, E. J., \& Schmelkin, L. P. Measurement, design, and analysis. Hillsdale, NJ: Lawrence Erlbaum, 1991.

[16] Gerstman, B. B. Basic Biostatistics: Statistics for Public Health Practice. Boson Jones and Bartlett, 2008.

[17] Nunnaly , J. C., \& Bernstein, I. H. (1994). Psychometric theory (3rd ed.). New York: McGraw-Hill.

[18] Mulhall A, May AL, Alexander C. Research based nursing practice--an evaluation of an educational programme. Nurse Educ Today. 2000; 20(6): 435-442. PMid:10959131 http://dx.doi.org/10.1054/nedt.2000.0499

[19] Wallin L, Bostrom AM, Gustavsson JP. Capability Beliefs Regarding Evidence-Based Practice are Associated with Application of EBP and Research Use: Validation of a New Measure. Worldviews on evidence-based nursing / Sigma Theta Tau International, Honor Society of Nursing 2012. 